\title{
Correction to: Mechanical and functional validation of a perfused, robot-assisted partial nephrectomy simulation platform using a combination of 3D printing and hydrogel casting
}

\author{
Rachel Melnyk ${ }^{1} \cdot$ Bahie Ezzat $^{3} \cdot$ Elizabeth Belfast $^{1} \cdot$ Patrick Saba $^{1} \cdot$ Shamroz Farooq $^{2} \cdot$ Timothy Campbell $^{2}$. \\ Stephen McAleavey ${ }^{3} \cdot$ Mark Buckley $^{3} \cdot$ Ahmed Ghazi $^{1}$
}

Published online: 20 January 2020

(c) Springer-Verlag GmbH Germany, part of Springer Nature 2020

\section{Correction to: World Journal of Urology https://doi.org/10.1007/s00345-019-02989-z}

The Eqs. 1, 2 and 3 come under the section "Kidney cortex testing" as per the original manuscript, but they have been incorrectly moved and separated into different sections in the original publication of the article.
The original article can be found online at https://doi.org/10.1007/ s00345-019-02989-z.
Now, the original article has been corrected.

Publisher's Note Springer Nature remains neutral with regard to jurisdictional claims in published maps and institutional affiliations.

\author{
Ahmed Ghazi \\ ahmed_ghazi@URMC.rochester.edu \\ Rachel Melnyk \\ Rachel_Melnyk@URMC.Rochester.edu \\ Bahie Ezzat \\ bezzat@u.rochester.edu \\ Elizabeth Belfast \\ ebelfast@ur.rochester.edu \\ Patrick Saba \\ Patrick_Saba@URMC.Rochester.edu \\ Shamroz Farooq \\ Shamroz_Farooq@URMC.Rochester.edu \\ Timothy Campbell \\ Timothy_Campbell@URMC.Rochester.edu
}

Stephen McAleavey
stephen.mcaleavey@ rochester.edu

Mark Buckley

mark.buckley@ rochester.edu

1 Department of Urology, Simulation Innovation Laboratory, Univeristy of Rochester Medical Center, 601 Elmwood Ave, Rochester, NY 14642, USA

2 School of Medicine and Dentistry, University of Rochester Medical Center, 601 Elmwood Ave, Rochester, NY 14642, USA

3 Department of Biomedical Engineering, Hajim School of Engineering, University of Rochester, 500 Joseph C. Wilson Blvd, Rochester, NY 14611, USA 